\title{
Acute myelogenous leukemia - current recommendations and approaches in molecular-genetic assessment
}

\author{
DINNAR YAHYA ${ }^{1,2}$, MARI HACHMERIYAN $^{1,2}$, ILINA MICHEVA $^{3,4}$, TRIFON CHERVENKOV $^{1,5}$
}

\author{
${ }^{1}$ Department of Medical Genetics, Faculty of Medicine, Medical University of Varna \\ ${ }^{2}$ Laboratory of Medical Genetics, UMHAT St. Marina, Varna \\ ${ }^{3}$ Department of Internal Diseases, Faculty of Medicine, Medical University of Varna \\ ${ }^{4}$ Clinic of Hematology, UMHAT St. Marina, Varna \\ ${ }^{5}$ Laboratory of Clinical Immunology, UMHAT St. Marina, Varna
}

\begin{abstract}
Acute myelogenous leukemia is a multi-step hematological malignancy, affecting function, growth, proliferation and cell cycle of myeloid precursors. Overall assessment of patients with the disease requires among everything else, a comprehensive investigation of the genetic basis through various methods such as cytogenetic and molecular-genetic ones. This clarification provides diagnostic refinement and carries prognostic and predictive value in respect of essential therapeutic choices.

With this review of the literature, we focus on summarizing the latest recommendations and preferred genetic methods, as well as on emphasizing on their general benefits and limitations. Since none of these methods is actually totipotent, we also aim to shed light over the often-difficult choice of appropriate genetic analyses.
\end{abstract}

Key words: leukemia, myeloid, acute, genetic markers, genetic techniques, diagnosis, prognosis.

\section{BACKGROUND}

Acute myelogenous leukemia (AML) is a heterogeneous group of disorders, caused by an abnormal proliferation of myeloid progenitor cells. It is typically seen in patients older than 45 years of age and represents roughly $80 \%$ of all leukemia cases in adults. Still, AML is considered a rare disease with a frequency of 4.2 in 100,000 people, with a slight predilection of males over females [1].

As with other malignancies, AML is known to be a result of the clonal expansion of multiple genetic and epigenetic events, originating from a single cell. Mainly acquired, these structural and functional changes in DNA lead to impaired hematopoiesis with effect on proliferation, differentiation, maturation, apoptosis and cell cycle control. AML characterizes with genetic heterogeneity, fast evolution and variable prognosis. These qualities complicate the diagnostic process and demand for a precise and efficient collaboration between involved specialists from various fields - clinical hematology, medical genetics, pathology, clinical immunology etc. Additionally, clarifying the exact constellation of genetic events that lead to a certain case is essential for diagnostic assessment as well as for evolution prognosis and therapy response prediction [1].

Diagnostically, genetic assessment is based on the conventional cytogenetic analysis (CCA), incorporated in classification and risk stratification of patients. Its well-known limitations, such as low resolution, long turnaround time and possible lack of metaphase plates, necessitate the implementation of subsidiary molecular-genetic methods [2].

In the era of molecular medicine, biomarkers play a major role in approach personalization. According to the World Health Organization (WHO), biomarkers are substances, structures or processes that could be measured in order to predict the outcome of a certain disease [3,4]. In a broader and commoner context, they are of use for various types of assessment with three main aspects:

- diagnostic - evaluation of the presence of a certain nosological entity;

- prognostic - assessment of outcome, especially after standard therapy application, or of therapy response amongst patients with similar laboratory, morphological and/or genetic characteristics; 
- predictive - evaluation of utility of certain therapy or several types of therapy in regards to sensitivity and potential resistance [4].

Hence, biomarkers enhance each case's processing from the beginning in respect of diagnosis identification, therapeutic decisionmaking and prediction of remission, relapse, overall, event-free survival etc. Thus, finding new and diverse biomarkers for various diseases is a matter of intense scientific labour in these years. As for the molecular markers, they are a subtype of biomarkers that consist of segments of the genome, referring to certain changes in the DNA sequence, levels of RNA expression or protein characteristics [4].

All of the genetic events that underlie a leukemic process, or their lack with a registered biallelic wild type, are in fact molecular-genetic markers. The latter can affect different aspects of the cell life and function. When registered, this essential presence or absence promotes better understanding, specification, prediction, managing and monitoring of the evolution of neoplastic process. Implementation of molecular markers with such a purpose - improving the therapeutic approach in a certain case, is the foundation of the so-called personalized medicine [5].

\section{CLASSIFICATIONS}

Reaching reasonably comprehensive understanding of the essence of AML necessitates the creation and implementation of classifications. There are two commonly used ones that require mentioning - French-American-British (FAB) and WHO's classification. The former dates back from 1976 and its foundation lies on the blasts' morphological characteristics, seen under a light microscope [6]. This collaborative work describes features that correlate with laboratory and clinical findings, as well as with therapeutic outcomes. It is helpful in differentiation of AML from Acute lymphoid leukemia and of various subtypes of AML. The classification is applicable for untreated patients only due to the changes, caused by chemotherapeutic medications. In addition, according to the FAB classification, blast cells have to have no less than $30 \%$ presence in bone marrow or peripheral blood. Samples are evaluated through histochemical Wright or Wright-Giemsa stain with the assessment of one or more malignant cell lines [7].

FAB classification is an important step towards a better understanding of the group of diseases that AML is. Still, it is far from thorough enough for contemporary daily clinical practice. This is due to the unstable correlation between morphological and cytochemical findings on one hand, and between molecular mechanisms and clinical variability on the other [8].

Clarification and understanding of the genetic characteristics ameliorate the mentioned disadvantage of the FAB classification. These also enhance our knowledge of etiology, pathogenesis, prognosis and therapeutic decision-making in AML. WHO's classification, with its first edition in 2001, is a pioneer in incorporating genetic features in AML subtype definition [9]. It is still perceived as a gold standard due to its comprehensiveness [6]. The latest revision of the WHO classification, presented in Table 1 , was released in 2016 [10].

As seen from the table, genetic changes have a significant place in this classification and their presence defines a certain subtype. Another essential difference from the FAB featured characteristics is the minimal amount of blast cells needed - WHO establishes a threshold of $20 \%$ as sufficient for the diagnosis. Additionally, chromosomal aberrations such as $\mathrm{t}(8 ; 21)$ $(\mathrm{q} 22 ; \mathrm{q} 22), \mathrm{t}(15 ; 17)(\mathrm{q} 22 ; \mathrm{q} 12), \mathrm{t}(16 ; 16)(\mathrm{p} 13 ; \mathrm{q} 22)$ or $\operatorname{inv}(16)(\mathrm{p} 13 ; \mathrm{q} 22)$ determine a diagnosis of AML regardless of blast load [8].

AML with recurrent genetic abnormalities:

$>\quad$ AML with $\mathrm{t}(8 ; 21)(\mathrm{q} 22 ; \mathrm{q} 22.1) ; \mathrm{RUNX} 1-\mathrm{RUNX} 1 \mathrm{~T} 1$

$>$ AML with inv(16)(p13.1q22) or t(16;16)(p13.1;q22);CBFB-MYH11

$>$ APL with PML-RARA

$>$ AML with $\mathrm{t}(9 ; 11)(\mathrm{p} 21.3 ; \mathrm{q} 23.3) ;$ MLLT3-KMT2A

$>$ AML with $\mathrm{t}(6 ; 9)(\mathrm{p} 23 ; \mathrm{q} 34.1) ;$ DEK-NUP214

$>$ AML with inv(3)(q21.3q26.2) or t(3;3)(q21.3;q26.2); GATA2, MECOM

$>$ AML (megakaryoblastic) with $\mathrm{t}(1 ; 22)(\mathrm{p} 13.3 ; \mathrm{q} 13.3) ; \mathrm{RBM} 15-\mathrm{MKL} 1$

$>$ Provisional entity: AML with BCR-ABL1 


\begin{tabular}{|l|}
\hline$>$ AML with mutated NPM1 \\
$>\quad$ AML with biallelic mutations of CEBPA \\
$>\quad$ Provisional entity: AML with mutated RUNX1 \\
\hline AML with myelodysplasia-related changes \\
\hline Therapy-related myeloid neoplasms \\
\hline AML, NOS \\
\hline AML with minimal differentiation \\
\hline AML without maturation \\
\hline AML with maturation \\
\hline Acute myelomonocytic leukemia \\
\hline Acute monoblastic/monocytic leukemia \\
\hline Pure erythroid leukemia \\
\hline Acute megakaryoblastic leukemia \\
\hline Acute basophilic leukemia \\
\hline Acute panmyelosis with myelofibrosis \\
\hline Myeloid sarcoma \\
\hline Myeloid proliferations related to Down syndrome \\
\hline Transient abnormal myelopoiesis (TAM) \\
\hline Myeloid leukemia associated with Down syndrome \\
\hline
\end{tabular}

\section{RISK STRATIFICATION}

Everything, described so far, demonstrates the heterogeneous, complex and individual nature, and therefore approach, of each case of AML. For this reason, it is essential to establish algorithms in order to precise the diagnostic and therapeutic processes. Along with the clinical, morphological, laboratory and statistical assessment methods, there is a routinely used European Leukemia Net (ELN) risk stratification. A current gold standard, it is committed to prediction of favourable, intermediate or adverse prognosis. ELN risk stratification serves as a "genetic triage", based on cytogenetic or singlegene findings. Overall 5-year survival that correlates with these three categories is $60 \%, 40 \%$ and $20 \%$, respectively [2]. The stratification is a product of international expert panel collaboration in 2010 [11] with a latest update in 2017, shown in Table 2 [12].

Table 2

2017 ELN risk stratification based on genetic findings (Dohner et al., 2017)

\begin{tabular}{|c|c|}
\hline Risk category & Genetic abnormality \\
\hline Favourable & $\begin{array}{ll}> & \mathrm{t}(8 ; 21)(\mathrm{q} 22 ; \mathrm{q} 22.1) ; \mathrm{RUNX} 1-\mathrm{RUNX} 1 \mathrm{~T} 1 \\
> & \text { inv(16)(p13.1q22) or } \mathrm{t}(16 ; 16)(\mathrm{p} 13.1 ; \mathrm{q} 22) ; \text { CBFB-MYH11 } \\
> & \text { Mutated NPM1 without FLT3-ITD or with FLT3-ITDlow } \\
> & \text { Biallelic mutated CEBPA }\end{array}$ \\
\hline Intermediate & $\begin{array}{ll}> & \text { Mutated NPM1 and FLT3-ITDhigh } \dagger \\
> & \text { Wild-type NPM1 without FLT3-ITD or with FLT3-ITDlow (without adverse-risk genetic } \\
& \text { lesions) } \\
> & \mathrm{t}(9 ; 11)(\mathrm{p} 21.3 ; \mathrm{q} 23.3) ; \text { MLLT3-KMT2A } \\
> & \text { Cytogenetic abnormalities not classified as favorable or adverse }\end{array}$ \\
\hline Adverse & $\begin{array}{ll}> & \mathrm{t}(6 ; 9)(\mathrm{p} 23 ; \mathrm{q} 34.1) ; \text { DEK-NUP214 } \\
> & \mathrm{t}(\mathrm{v} ; 11 \mathrm{q} 23.3) ; \text { KMT2A rearranged } \\
> & \mathrm{t}(9 ; 22)(\mathrm{q} 34.1 ; \mathrm{q} 11.2) ; \mathrm{BCR}-\mathrm{ABL} 1 \\
> & \text { inv }(3)(\mathrm{q} 21.3 \mathrm{q} 26.2) \text { or } \mathrm{t}(3 ; 3)(\mathrm{q} 21.3 ; \mathrm{q} 26.2) ; \text { GATA2,MECOM(EVI1) } \\
> & -5 \text { or del(5q);-7;-17/abn(17p) } \\
> & \text { Complex karyotype, monosomal karyotype } \\
> & \text { Wild-type NPM1 and FLT3-ITDhigh } \\
> & \text { Mutated RUNX1 } \\
> & \text { Mutated ASXL1 } \\
> & \text { Mutated TP53 }\end{array}$ \\
\hline
\end{tabular}


Some clarifications, needed with the information on this table, are:

- The prognostic value of these markers could change in time with the implementation of new types of therapy;

- The presence of $t(9 ; 11)(\mathrm{p} 21.3 ; \mathrm{q} 23.3)$ is of higher predictive value than rarer aberrations, associated with an adverse risk;

- Complex karyotype is defined as three or more non-related chromosomal aberrations in absence of a common aberration, indicated in the WHO classification, such as $\mathrm{t}(8 ; 21), \operatorname{inv}(16 ; 16), \mathrm{t}(16 ; 16), \mathrm{t}(9 ; 11), \mathrm{t}(6 ; 9)$, $\mathrm{t}(\mathrm{v} ; 11 \mathrm{q} 23.3), \mathrm{t}(9 ; 22)$, inv(3) or $\mathrm{t}(3 ; 3)$;

- Monosomal karyotype identifies with a singular monosomy (except for a sexchromosomal one) in association with at least one additional monosomy or structural chromosomal aberration (except for those involving a core binding factor (CBF) encoding gene) [12].

Routinely used tools such as WHO classification and ELN risk stratification incorporate some of the molecular markers due to the comprehensive mapping, investigation and confirmation of the latter as essential for understanding the highly heterogeneous AML. Figure 1 demonstrates some of these genes, grouped in accordance with their function.

As seen in the figure, some of the genes involved and the respective mutations' effects are relatively well-known. However, far from all of them are incorporated in the current guidelines for clinical assessment. This suggests the need for a more thorough look through their utility and possible implementation in routine evaluation of patients with AML [13].

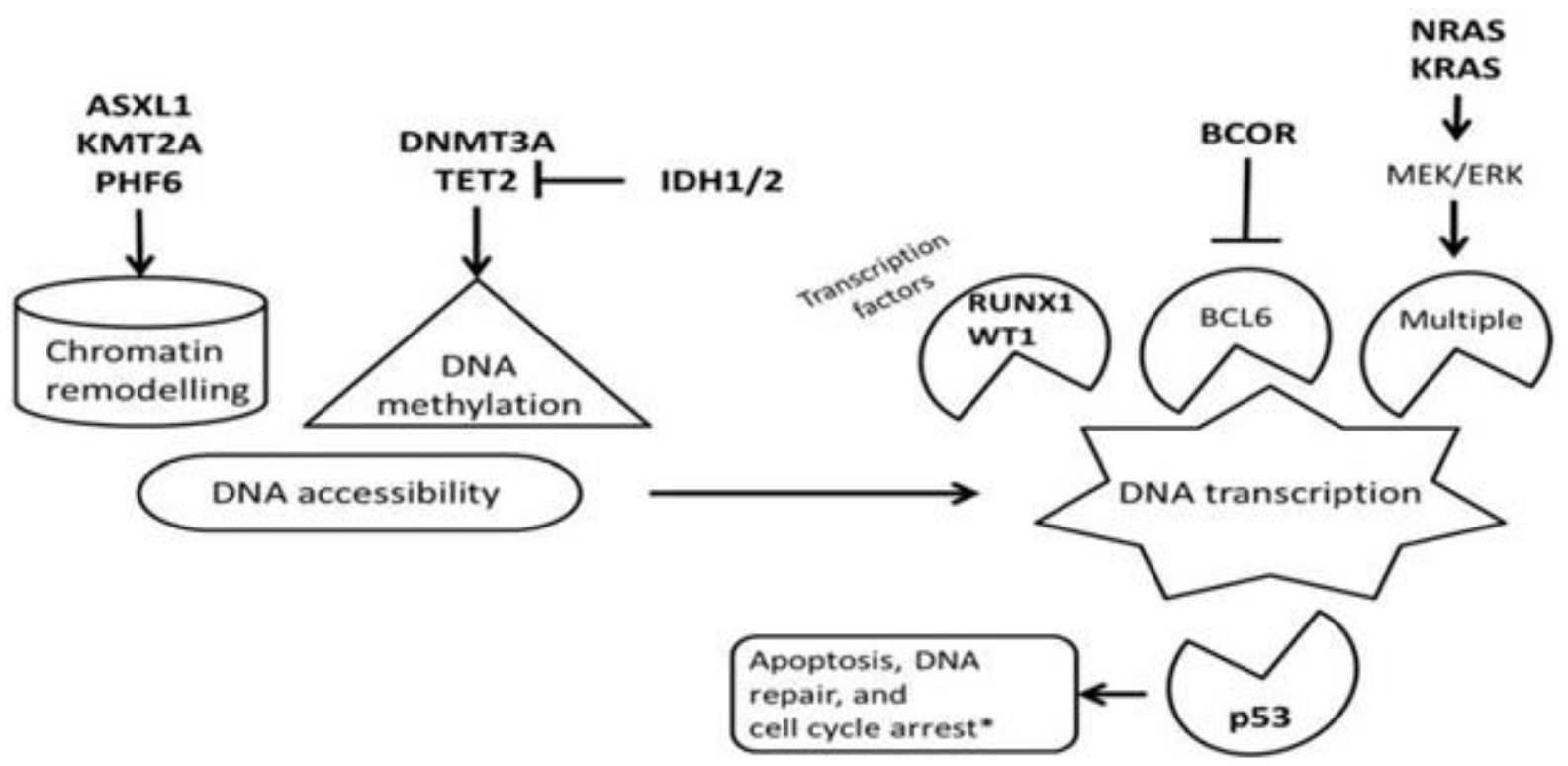

*via transcriptional and non-transcriptional effects

Figure 1. Genes that participate in the leukemic process in AML and their effects on transcription (Yohe, 2015) [13].

\section{PEDIATRIC AMI}

Even though AML is mostly seen in adults, it affects children as well. Since the latter present as a separate and specific contingent, the hematological malignancy in this context has quite different characteristics in comparison to the adult population. Firstly, children with AML generally have a more favourable outcome due to the less frequent adverse prognosis mutations. Unfortunately, relapse is still seen in nearly half of the patients so it remains a challenge for the pediatric oncologists.

As for the genetics, most common chromosomal changes here are $\mathrm{t}(8 ; 21)$ and $\operatorname{inv}(16)$, seen in $20-25 \%$ of cases. Other than that, cryptic translocations are frequent contributors to the neoplastic process. Regarding molecular- 
genetics findings, Ras pathway genes - HRAS, KRAS, are the most commonly mutated ones $40 \%$ of all. They carry prognostic means in certain subtypes as well as being a possible therapeutic target. FLT3 mutations are typical for roughly $25 \%$ of cases with more commonly seen FLT3-ITD in comparison to adults, with a prognostic value depending on the allelic ratio. KMT2A mutations are more frequent in children with a prognostic value depending on the fusion gene present. Also, KIT and WT1 are commonly mutated, while NPM1 mutations are a rarer finding in this population. All of these differences facilitate the rather distinct approach and caution needed in pediatric AML. Among the current classifications and recommendations used to provide guidance are WHO, ELN as well as the Therapeutically Applicable Research to Generate Effective Treatments (TARGET) [14,15].

\section{MOLECULAR-GENETIC ASSAYS}

Cytogenetic evaluation of the genetic background of an AML case has an unquestionable contribution in outcome prognosis and therapeutic choice [13]. Since prognostic genetic markers are those included in WHO classification and ELN risk stratification, cytogenetic analysis holds its essential role in assessment. It has the ability to encompass largescale mutations such as deletions, duplication, inversions, translocations, including balanced and Robertsonian, as well as ring and marker chromosomes [16]. Nevertheless, moleculargenetic markers require methods of superior resolution. There are two main genome methods that contribute to advance in discovery and understanding of molecular-genetic markers SNP (single nucleotide polymorphism) microarray and Next-generation sequencing (NGS) $[17,18,19,20]$. For now, ELN recommends screening that includes at least 6 moleculargenetic markers in all newly diagnosed AML patients - FLT3, NPM1, CEBPA, RUNX1, TP53, ASXL1, and the gene fusions PML-RARA, CBFB-MYH11, RUNX1-RUNX1T1 and BCRABL1, in addition to cytogenetic analysis $[12,21]$. National Comprehensive Cancer Network (NCCN) adds 3 more markers - IDH1, IDH2 and c-KIT. There is a noteworthy difference between these two systems that regards patients with a mutation in CBF - ELN classifies them into favourable prognosis while NCCN - into intermediate, when in combination with c-KIT mutation [21]. Table 3 demonstrates some of the commonly used markers together with the prognostically significant cytogenetic configuration.

Table 3

Molecular-genetic findings in combination with a clinical significance-relevant cytogenetic profile (Weinberg et al., 2017) [14]

\begin{tabular}{|l|l|l|}
\hline Molecular Genetic Alteration & Cytogenetic group & Prognostic significance \\
\hline KIT mutation & $\mathrm{t}(8 ; 21)(\mathrm{q} 22 ; \mathrm{q} 22.1)$ & Poor \\
\hline FLT3-ITD & Normal karyotype & Poor \\
\hline Biallelic CEBPA mutations & Normal karyotype & Favourable \\
\hline Single CEBPA mutation & Normal karyotype & Poor, compared to patients with biallelic ones \\
\hline NPM1 mutation (without FLT3-ITD* mutation) & Normal karyotype & Favourable \\
\hline RUNX1 mutation & Normal karyotype & Poor \\
\hline WT1 mutation & Normal karyotype & Poor \\
\hline TET2 mutation & Normal karyotype & Poor \\
\hline ASXL1 mutation & Normal karyotype & Poor \\
\hline DNMT3A mutation & Normal karyotype & Poor \\
\hline TP53 mutation or loss & Complex karyotype & Poor \\
\hline
\end{tabular}

*ITD - internal tandem duplication

As demonstrated in the table, these markers require preliminary clarification of the karyotype. In addition, there is a need for a convenient molecular-genetic method that is able to register the exact mutation with its specific type and size. Moreover, isolated genetic events are quite rare in neoplastic processes, so even after a general mutation has been identified the investigation usually continues until the genetic constellation is clear [17]. This characteristic might suggest the implementation of several molecular-genetic methods given their individual advantages and limitations (Table 4) [20]. 
Table 4

Features of molecular-genetic methods used in the diagnostics and clinical approach to some oncohematologic diseases (Berry et al., 2019) [20]

\begin{tabular}{|l|l|l|l|l|l|l|}
\hline & Resolution & $\begin{array}{l}\text { Whole } \\
\text { genome } \\
\text { analysis }\end{array}$ & $\begin{array}{l}\text { cnLOH } \\
\text { detection }\end{array}$ & $\begin{array}{l}\text { Dividing cells } \\
\text { required }\end{array}$ & Sensitivity & $\begin{array}{l}\text { Balanced } \\
\text { rearrangement } \\
\text { detection }\end{array}$ \\
\hline CCA & $<5 \mathrm{Mb}^{*}$ & Yes & No & Yes & $10 \%$ & Yes \\
\hline FISH & $100-300 \mathrm{~kb}^{\dagger}$ & No & No & No & $5-10 \%$ & Yes \\
\hline $\begin{array}{l}\text { SNP- } \\
\text { microarray }\end{array}$ & $3-10 \mathrm{~kb}$ & Yes & Yes & No & $5-20 \%$ & No \\
\hline $\begin{array}{l}\text { Fusion gene } \\
\text { sequencing } \\
\text { panels }\end{array}$ & $<1 \mathrm{~kb}$ & No & No & No & $<5-10 \%$ & Yes \\
\hline NGS / MPS & $<1 \mathrm{~kb}$ & Yes & No & No & $5-10 \%$ & Yes $^{\S}$ \\
\hline
\end{tabular}

*mb - megabases, 1 million nucleotides in length

${ }^{\dagger} \mathrm{kb}$ - kilobases, 1000 nucleotides in length

¥MPS - Massive parallel sequencing

${ }^{\S}$ Referring to specifically designed NGS panels or MPS techniques

\section{SNP-MICROARRAY}

SNP-microarray is a microchip-based genomic method, a variant of Chromosomal microarray analysis (CMA). It is performed with the use of probes, specific for single nucleotide polymorphisms (SNPs) as markers for genomic changes. The method surpasses the conventional CMA due to its ability to register not only quantitative imbalances such as microdeletions and amplifications, but also loss of heterozygosity and ploidies that the latter would miss $[19,20]$. Additionally, SNP-microarray has the ability to identify interstitial deletions, seen in $25 \%$ of gene fusions. These fusions are originally defined as balanced changes and in lack of such deletions, they would not be detected. Hence, the method is applicable for small-scale mutations up to 10 base pairs (bp). Loss of heterozygosity, where a deleted normal allele is "salvaged" through duplication of the mutated one, as well as quantitative changes such as hypodiploidy, hyperdiploidy etc. are also quite common cooperators in leukemogenesis that carry certain prognostic values. Thus, identifying them is highly significant in order to personalize the approach.

Another important advantage of the method refers to marker and ring chromosomes. In CCA these findings usually remain with an unclarified origin, whereas SNP-microarray is able to identify them and their exact origin easily.

As for the disadvantages of this method, there are few important ones to note. Firstly, balanced changes are not amongst the range of detection of SNP-microarray. Secondly, it has a sensitivity of
$10 \%$ in regards to clonality, which makes the method improper for Minimal/measurable residual disease (MRD) monitoring. Thirdly, the resolution limits the detection of essential single-gene mutations such as those in FLT3, NPM1, C-KIT, RUNX1, CEBPA, IDH1, IDH2, JAK2 and some in TP53, since they affect one or several bp only. These limitations suggest that SNP-microarray is not sufficient for a singular molecular-genetic diagnostic and prognostic method, and should be complemented by another one in order to provide thorough and precise assessment [20].

\section{NGS}

The broad term NGS incorporates several methods that share the same aim but differ in precise technique and capacity. In a matter of several hours or days, NGS methods manage to read a certain nucleic acid sequence in a parallel manner with an accuracy of up to one nucleotide. The differences between the methods refer to the subject of sequencing and its length:

- Whole genome sequencing - subjects the entire aggregate of coding and non-coding regions

- Whole exome sequencing - concerned with the sum of coding regions, or exome, only

- Targeted sequencing - aims at preliminarily chosen segments of the genome, such as a disease-related gene panel

- Deep sequencing - this variation manages to register clones smaller than $1 \%$ that is an enormous accomplishment in comparison with the other types as well as in comparison with other molecular-genetic methods in general [21]. 
The use of NGS contributed to the discovery of several aspects of the leukemic process initiation, improving the understanding of it and therefore the personalization possibilities [17,22]. For example, clonal hematopoiesis of indeterminate potential (CHIP), is defined as presence of acquired initiating mutations with 10$20 \%$ allelic frequency in TET2, DNMT3A, ASXL1, GNAS, PPM1D, or SF3B1 (Splicing factor 3b, subunit 1) genes, in otherwise healthy elderly individuals. Regardless of their well-known significance, it seems that these early genetic events are insufficient to solely cause a neoplastic process development. However, CHIP increases the risk of myelogenous malignancy development by $1 \%$ per year. Additionally, there is a doubling in respect of coronary heart disease [22]. Another relevant condition - Clonal hematopoiesis with substantial oncogenic potential (CHOP), consists of AML-characteristic driver mutations in FLT3, KRAS, HRAS, BCR-ABL, JAK2, RUNX1 with high allelic frequency. CHOP resembles AML even more closely since it is usually a few genetic events away from transformation into hematological malignancy, yet it does not fulfill the criteria for the disease $[21,23]$.

Nowadays NGS stands as a method with predictive and prognostic application other than diagnostic one. Regardless of the continuing need for result validation, the method could contribute in regards to targeted therapy selection, response assessment, and evaluation of risk of relapse after allogeneic stem cell transplantation.

Until recently, NGS was thought to be mostly suitable for small-scale mutations and this was one of its disadvantages. Still, the method proves to be overcoming this limitation and is steadily introduced in research and practice as an appropriate for detection of structural variations such as copy number variations, translocations and larger indels $[16,25]$. This tendency is quite promising in the means of the possibility to choose a proper singular molecular assay for the assessment of AML patients.

As for MRD monitoring, NGS demonstrates potential advantages in comparison with other, already used methods such as flow cytometry and Real-time PCR. Such advantage is the total number of genes that could be sequenced in order to acquire a comprehensive evaluation of the impermanent genetic background [17,21]. However, perfect timing and frequency of analyses, as well as the exact set of genes have not been specified yet. Additionally, some challenges exist, such as sensitivity limitations for non-deep sequencing. Other noteworthy disadvantages refer to still-existing appreciable artifacts, library preparation-related variable noise and $1 \%$ error probability $[17,26]$.

Current recommendations support, but do not necessitate the use of NGS as a particular molecular-genetic method for classification and risk stratification in addition to CCA [12]. There are several gene panels for analysis of myeloid neoplasm-associated genes, available on the market. They differ in the amount of genes included with Qiagen Human Myeloid Neoplasms Panel and Illumina AmpliSeq Myeloid Panel being the most numerous ones [26]. This promotes NGS to successful incorporation in routine clinical assessment [17]. Additionally, it is also frequently the choice in the work-up of pediatric cases [24]. Other than the already mentioned limitations, still relatively high price should be taken into account, as well as specifications of some genes such as the GC-rich CEBPA, and FLT3-ITD mutations with variable amplicon length, that complicate their sequencing. In addition, loss of heterozygosity - a significant mechanism in AML pathogenesis, remains outside the range of NGS methods (Table 4) [20]. Controversially, gene fusion detection is in fact with a shorter turnaround time with qPCR than with NGS [21]. As mentioned, validation through Sanger sequencing is still required despite the opinion of this to be unnecessary in recent literature [27]. To conclude, additional research is needed in order to clarify and precise the possibilities and incorporation of the method in routine clinical practice.

\section{SANGER SEQUENCING}

Sanger sequencing, dating from the 1970 's, is a gold-standard method in nucleotide identification. The development of the method continued for several years until its final version, announced in 1977, including the essential radioactively labeled dideoxynucleotides. Naturally, some changes were introduced through the years, for example replacing the hazardous radioactive labeling with a safer, fluorescent one. Additionally, capillary electrophoresis and general automatization of the process made sequencing several fragments synchronously a routine feature [28]. 
A leading disadvantage of Sanger sequencing (Table 4) would be the fragment size limitation - up to 1,000 nucleotides, that refrains the method from being a whole-genome one. This is especially inconvenient for malignancies where several changes, distant from each other, are expected to be present simultaneously. Another weakness refers to lack of sensitivity towards loss of heterozygosity [20]. The clarity and precision of Sanger sequencing have secured its place as a gold standard and confirmatory method for decades following its introduction. Still, there is a progressing tendency for replacing it with more potent and recent methods such as NGS, SNP array, polymerase chain reaction (PCR) and others [17,21]. Regardless of this tendency, Sanger sequencing is in current use as a moleculargenetic method in the diagnostic process and prognostication of patients with AML, especially in combination with PCR. Thus, it can be applied for assessment of small-scale mutations in certain genes along with CCA or FISH as methods with lower resolution. Sanger sequencing has the benefit of successfully detecting mutations in CGrich essential genes such as CEBPA in contrast to NGS [29]. Also, this method has an essential role in cases with novel mutations and their required confirmation [30,31]. This will likely continue until the official designation of the mentioned newer methods as self-confirmatory.

\section{PCR}

PCR consists of several consecutive stages, performed repeatedly at preliminarily set temperature variations. This facilitates amplification of a desired nucleic acid fragment for a short period of time into millions of copies - amplicons [32].

Nowadays PCR has a range of implementation that is much broader than its original application as an amplification step. Along with the existing variations, it is currently a preferred and competitive method for screening and detection of either normal or aberrant target sequences with a known mutation. As for AML, mutations in NPM1, FLT3, DNMT3A, IDH2, IDH2 and other essential genes can be successfully registered $[33,34,35]$. A variant, called Real-time PCR (Quantitative PCR, qPCR) is especially helpful using fluorescent markers and their respective sensors, facilitating quantitative evaluation of the amplicons in real time [32]. The features of qPCR - sensitivity, specificity and straightforward interpretation, promote its suitability for monitoring of low-grade changes, typical for MRD [17,36]. Another significant advantage of this subtype in particular is the ability to register loss of heterozygosity [37]. As mentioned, PCR techniques are currently applied for quick screening of small-scale mutations, commonly in combination with Sanger sequencing as a confirmatory method [26]. They are also commonly used in the assessment of pediatric AML cases [38].

Nevertheless, PCR has its limitations, such as the targeted nature of the analysis, so just like Sanger sequencing, it cannot be implemented as a whole-genome assay. In addition, both the normal and the variant sequence have to be antecedently known in order to synthesize complementary primers. Moreover, there is a possibility of nonspecific hybridization of the latter, and therefore a likelihood of false-positive results, or DNA polymerase inconsistencies [39]. These characteristics suggest the need for a confirmatory method. Regardless, PCR techniques progress in a continuous manner, and with that, many of the mentioned limitations are likely to be soon diminished [37].

\section{MLPA}

Multiplex ligation-dependent probe amplification (MLPA) derives from the aforementioned PCR method, and the amplification that marks its success depends on the ligation of two separate primers, complementary to the matrix. This enables the multiplex character of the reaction, similar to PCR's turnaround time, simple performance and high specificity. The semi-quantitative method consist of four consecutive stages:

- denaturation and hybridization of the single-stranded matrix with two separate primers

- ligation of the primers, executed by a highly sensitive to precise complementation ligase

- PCR of the new, ligation-derived fragment

- capillary electrophoresis fragment separation and consequent analysis.

MLPA holds a wider variety of applications due to the ability to register a broad scope of mutations, including the minutest ones (Figure 2). Thus, the method is applicable for both large- and small-scale mutations. Amongst this spectrum are variations in number of repeats, small deletions, point mutations, and even epigenetic changes such as methylation status are now a routine target. 


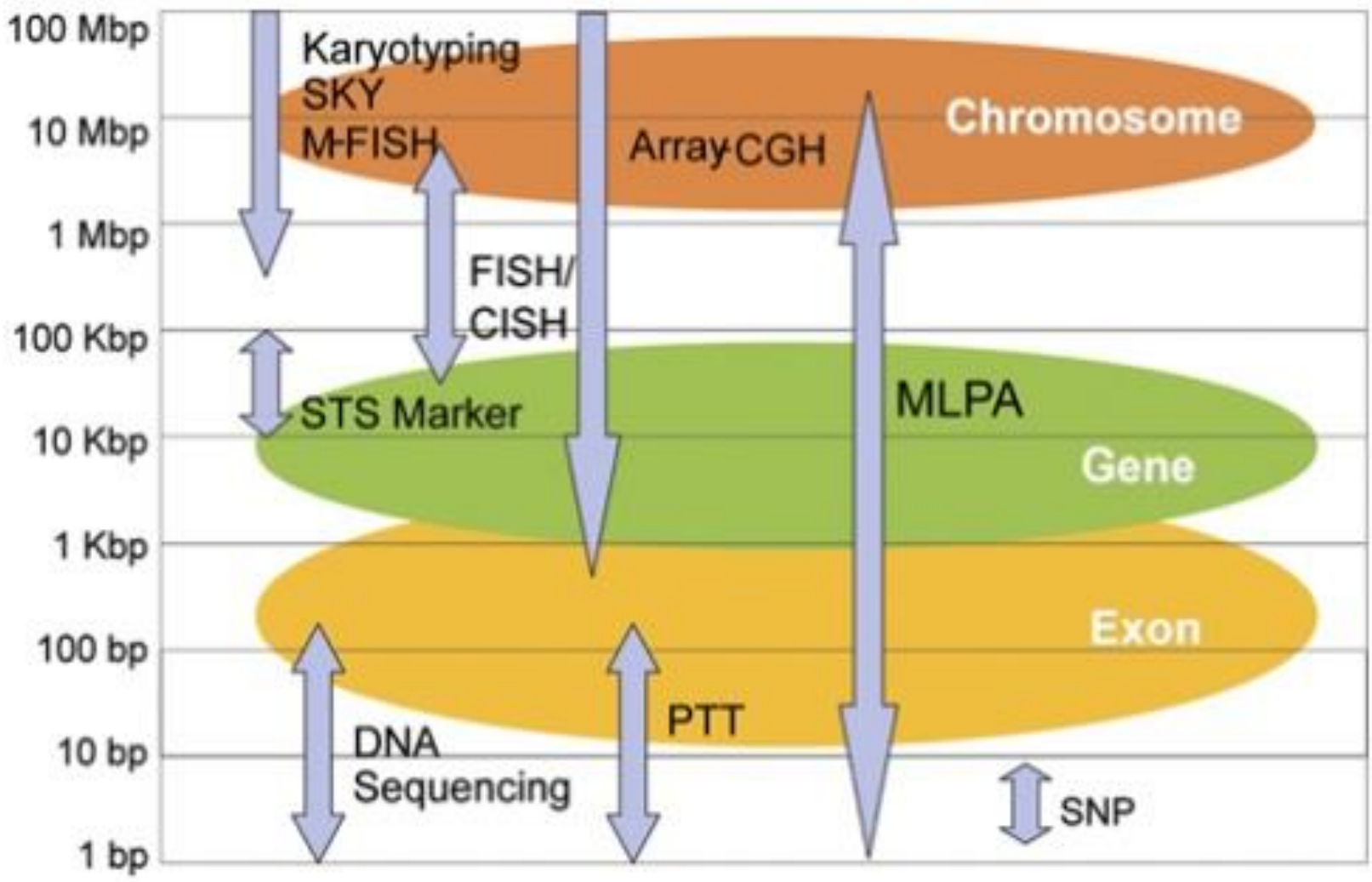

Figure 2. Analytical scope of some of the genetic methods (Hömig-Hölzel \& Savola, 2012) [40].

A significant advantage is also the great number of probes, applicable in a single reaction up to 50 currently. This feature improves the informativeness in comparison with PCR techniques. Hence, MLPA is more convenient for genetic analysis of patients with neoplastic processes where typically a constellation of genetic events is expected to underlie the disease. The material base of the method is standard - a thermocycler, capillary electrophoresis and analytical software - Coffalyser, the latter created by the developers of MLPA, MRC Holland. Moreover, there is a noticeable cost reduction of this type of analysis in comparison with other available ones [40]. These characteristics promote MLPA's position in the routine diagnostic process of various diseases, including hematological malignancies [41-45].

Among the disadvantages of the method, there is a dependence of its sensitivity on the size of the cell line. The latter has to be no less than $20 \%$ in order to detect a heterozygous deletion, and $40 \%$ for a duplication detection. In this aspect, other, already discussed methods (Table 4) outperform MLPA. Still, in terms of heterozygous point mutations and methylation status, it presents with competitive efficiency $-5-10 \%$ and $30 \%$, respectively. Another significant characteristic is that similarly to PCR, MLPA can only detect known point mutations due to the need for primers. Finally yet importantly, the method is not a whole-genome one, and it works with predetermined molecular-genetic targets. While this is suitable for diagnosis of malignancies, it might not be so for other types of pathology [40].

\section{CONCLUSION}

Current advances in science and technology can now provide a wide variety of molecular-genetic methods depending on the needs and resources of the diagnostic or clinical entity. The choice of such a method also relates to the amount and turnover of patients and therefore samples, as well as to material matters of recruitment, equipment and financing. Additionally, regularly updated recommendations are available to guide this decision. Finally but importantly stands the personnel qualification, for it ensures accurate and timely performance of the analyses, as well as selection, adaptation and 
incorporation of new ones. Put together, these factors determine the set of analyses in assessment of patients with a certain disease.

As for AML in particular, for both adults and children, current guidelines on molecular genetic diagnosis, risk stratification and prognosis include a combination of at least two genetic methods. Firstly, an initial CCA on bone marrow samples is necessary for proper risk stratification. Secondly, FISH or a moleculargenetic method such as the ones mentioned above to encompass more detailed changes in the genome $[12,46]$. The need for precise and rapidly acquired information regarding the present genetic background also alludes to this additional entity [47]. The exact combination of methods in addition to cytogenetics also depends on the current national healthcare politics and on the medical center's laboratory equipment and/or the possibility and practice of outsourcing such services. Given the discussed advantages and applications, and the literature suggesting a limited utility of FISH, selecting an actual molecular-genetic method as a subsidiary one might be more beneficial in regards to comprehensiveness [40,47]. Doing so would maintain a reliable whole-genome assessment and risk stratification on the one hand, as well as a rapid, simple and elaborate genetic characteristic on the other. This would provide precise and thorough information regarding the genetic origins of the process, leading to the best odds for a personalised approach and possible favourable outcome for the patient.

Leucemia acută mieloidă este o malignitate hematologică ce afectează ciclul celular, proliferarea și multiplicarea celulelor stem hematologice. Investigațiile pacienților necesită și un studiu genetic, ce poate indica prognosticul pentru pacient. Acest articol trece în revistă ultimele recomandări, precum şi metodele genetice utilizate (alături de limitele și performanța acestora). Totodată sunt prezentate indicațiile pentru a alege o metodă genetică.

Correspondence to: Dinnar Yahya, Department of Medical Genetics, Faculty of Medicine, Medical University of Varna, Hristo Smirnenski blv 1, 9000, Varna, Bulgaria

E-mail: yahyadinnar@gmail.com, telephone: +359 889113424

Conflict of interest disclosure: The authors declare that there are no conflicts of interest

\section{REFERENCES}

1. VAKITI A., MEWAWALLA P. Acute Myeloid Leukemia. In: StatPearls, StatPearls Publishing, Treasure Island (FL), 2021.

2. POGOSOVA-AGADJANYAN E., MOSELEY A., OTHUS M., APPELBAUM F. Chauncey T., Chen I. et al. AML risk stratification models utilizing ELN-2017 guidelines and additional prognostic factors: a SWOG report. Biomark Res. 2020, 8:29.

3. STRIMBU K., TAVEL J. What are biomarkers? Curr. Opin. HIV AIDS. 2010;5(6):463-466.

4. NAIR M., SANDHU S., SHARMA A., Cancer molecular markers: A guide to cancer detection and management. Seminars in Cancer Biology. 2018;52(1):39-55.

5. VERMA M. Personalized medicine and cancer. J Pers Med. 2012;2(1):1-14.

6. LADINES-CASTRO W., BARRAGAN-IBANEZ G., LUNA-PEREZ M., SANTOYO-SANCHEZ A., COLLAZO-JALLOMA J., MENDOZA-GARCIA E. et al. Morphology of leukaemias. Rev Med Hosp Gen Mex. 2016;79(2):107-113.

7. SCHIFFER C., STONE R. Morphologic Classification and Clinical and Laboratory Correlates. In: Holland-Frei Cancer Medicine. 6th edition. Hamilton (ON): BC Decker; 2003.

8. VARDIMAN J., HARRIS N., BRUNNING R. The World Health Organization (WHO) classification of the myeloid neoplasms. Blood. 2002; 100(7): 2292-2302.

9. BLUM W., BLOOMFIELD C. Acute Myeloid Leukemia. In: Harrison's Principles of Internal Medicine. McGraw-Hill, New York, 2018:739-748.

10. ARBER D., ORAZI A., HASSERJIAN R., THIELE J., BOROWITZ M., LE BEAU M. et al. The 2016 revision to the World Health Organization classification of myeloid neoplasms and acute leukemia. Blood. 2016; 127(20):2391-2405.

11. HEROLD T., ROTHENBERG-THURLEY M., GRUNWALD V., JANKE H., GOERLICH D., SAUERLAND M. et al. Validation and refinement of the revised 2017 European LeukemiaNet genetic risk stratification of acute myeloid leukemia. Leukemia. 2020;34:3161-3172.

12. DOHNER H., ESTEY E., GRIMWADE D., AMADORI S., APPELBAUM F., BUCHNER T. et al. Diagnosis and management of AML in adults: 2017 ELN recommendations from an international expert panel. Blood. 2017;129(4):424-447.

13. YOHE S. Molecular Genetic Markers in Acute Myeloid Leukemia. J Clin Med. 2015;4(3):460-78.

14. CONNEELY S., STEVENS A. Acute Myeloid Leukemia in Children: Emerging Paradigms in Genetics and New Approaches to Therapy. Curr Oncol Rep. 2021;23(2):16.

15. ELGARTEN C,. APLENC, R. Pediatric acute myeloid leukemia: updates on biology, risk stratification, and therapy. Current Opinion in Pediatrics. 2020;32(1):57-66 
16. ABEL H., DUNCAVAGE E. Detection of structural DNA variation from next generation sequencing data: a review of informatic approaches. Cancer Genet. 2013;206(12):432-440.

17. WEINBERG O., SOHANI A., BHARGAVA P., NARDI V. Diagnostic work-up of acute myeloid leukemia. Am J Hematol. 2017;92(3):317-321

18. NAIR M., SANDHU S., SHARMA A. Prognostic and Predictive Biomarkers in Cancer. Curr Cancer Drug Targets. 2014;14(5):477-504.

19. IBANEZ M., SUCH E., ONECHA E., GOMEZ-SEGUI I., LIQUIORI A., SELLES J. et al. Analysis of SNP Array Abnormalities in Patients with DE NOVO Acute Myeloid Leukemia with Normal Karyotype. Sci Rep. 2020;10(1):5904.

20. BERRY N., SCOTT R., ROWLINGS P., ENJETI A. Clinical use of SNP-microarrays for the detection of genome-wide changes in haematological malignancies. Crit Rev Oncol Hematol. 2019;142:58-67.

21. LEISCH M., JANSKO B., ZABORANSKY N., GREIL R., PLEYER L. Next Generation Sequencing in AML-On the Way to Becoming a New Standard for Treatment Initiation and/or Modulation? Cancers (Basel). 2019;11(2):252.

22. JAISWAL S., NATARAJAN P., SILVER A., GIBSON C., BICK A., SHVARTZ E. et al. Clonal Hematopoiesis and Risk of Atherosclerotic Cardiovascular Disease. N Engl J Med. 2017;377(2):111-121.

23. PAPAEMMANUIL E., GERSTUNG M., BUlliGER L., GAIDZIK V., PASCHKA P., ROBERTS N. et al. Genomic Classification and Prognosis in Acute Myeloid Leukemia. N Engl J Med. 2016;374(23):2209-2221

24. WOOLBRIGHT W., WONG V., SEVERSON E., KUO D. The Application of Next-generation Sequencing Tumor Molecular Profiling in the Diagnosis and Management of a Case of Acute Myelogenous Leukemia With MLL-PTD in a Pediatric Heart Transplant Recipient. Journal of Pediatric Hematology/Oncology. 2021;43(2):246-e249

25. HAN E., YOO J., CHAE H., LEE S., KIM D., KIM K. et al. Detection of BRCA1/2 large genomic rearrangement including BRCA1 promoter-region deletions using next-generation sequencing. Clin Chim Acta. 2020;505:49-54.

26. LEVINE R., VALK P. Next-generation sequencing in the diagnosis and minimal residual disease assessment of acute myeloid leukemia. Haematologica. 2019;104(5):868-871.

27. ARTECHE-LOPEZ A., ÁVILLA-FERNANDEZ A., ROMERO R., RIVEIRO-ÁLVAREZ R., LOPEZ-MARTINEZ A., GIMENEZ-PARDO A. et al. Sanger sequencing is no longer always necessary based on a single-center validation of 1109 NGS variants in 825 clinical exomes. Sci Rep. 2021; 11:5697.

28. HEATHER J., CHAIN B. The sequence of sequencers: The history of sequencing DNA. Genomics. 2016;107(1):1-8.

29. MENDOZA H., PODOLTSEV N., SIDDON A. Laboratory evaluation and prognostication among adults and children with CEBPA-mutant acute myeloid leukemia. Int J Lab Hematol. 2021;43 Suppl 1:86-95.

30. O'BRIEN G., ZYLA J., MANOLA K., PAGONI M., POLANSKA J., BADIE C. Identification of two novel mutations in human acute myeloid leukemia cases. Leuk Lymphoma. 2021;62(2):454-461.

31. TOKGUN P., ALAY M., ATLI TEKIN S., GULER N., TOKGUN O., DEMIRAY A. et al. Two Novel CEBPA Mutations in a Turkish Patient with Acute Myeloid Leukemia. Balkan J Med Genet. 2021;23(2):99-102.

32. PRAY L. The Biotechnology Revolution: PCR and the Use of Reverse Transcriptase to Clone Expressed Genes. Nature Education. 2008;1(1):94

33. GUO Y., SUN H., ZHANG D., ZHAO Y., SHI M., YANG M. et al. Development of a highly sensitive method for detection of FLT3D835Y. Biomark Res. 2020;8:30.

34. GORNIAK P., EJDUK A., BORG K., MAKUSH-LASIKA H., NOWAK G., LESH-MARANDA E. et al. Comparison of highresolution melting analysis with direct sequencing for the detection of recurrent mutations in DNA methyltransferase $3 A$ and isocitrate dehydrogenase 1 and 2 genes in acute myeloid leukemia patients. Eur J Haematol. 2016; 96:181-187.

35. KUMAR D., MEHTA A., PANIGRAHI M., NATH S., SAIKIA K. NPM1 Mutation Analysis in Acute Myeloid Leukemia: Comparison of Three Techniques - Sanger Sequencing, Pyrosequencing, and Real-Time Polymerase Chain Reaction. Turk J Haematol. 2018;35(1):49-53.

36. OMMEN H. Monitoring minimal residual disease in acute myeloid leukaemia: a review of the current evolving strategies. Ther Adv Hematol. 2016;7(1):3-16.

37. HUIJSMANS C., POODT J., DAMEN J., VAN DER LINDEN J., SAVELKOUL P., PRUJIT J. et al. (2012) Single Nucleotide Polymorphism (SNP)-Based Loss of Heterozygosity ( $\mathrm{LOH}$ ) Testing by Real Time PCR in Patients Suspect of Myeloproliferative Disease. PLoS ONE. 2012;7(7):e38362.

38. KSIAZEK T., CZOGALA M., KACZOWKA P., SADOWSKA B., PAWINSKA-WASIKOWSKA K., BIK-MULTANOWSKI M. et al. High Frequency of Fusion Gene Transcript Resulting From t(10;11)(p12;q23) Translocation in Pediatric Acute Myeloid Leukemia in Poland. Front Pediatr. 2020;8:278.

39. GARIBYAN L., AVASHIA N. Polymerase chain reaction. J Invest Dermatol. 2013;133(3):1-4.

40. HOMIG-HOLZEL C., SAVOLA S. Multiplex ligation-dependent probe amplification (MLPA) in tumor diagnostics and prognostics. Diagn Mol Pathol. 2012;21(4):189-206.

41. PAYNE A., BEAN C., HOOPER W., MILLER C. Utility of multiplex ligation-dependent probe amplification (MLPA) for hemophilia mutation screening. J Thromb Haemost. 2012;10(9):1951-4.

42. ALPAR D., DE JONG D., SAVOLA S., YIGITTOP H., KAJTAR B., KERESKAI L. et al. MLPA is a powerful tool for detecting lymphoblastic transformation in chronic myeloid leukemia and revealing the clonal origin of relapse in pediatric acute lymphoblastic leukemia. Cancer Genet. 2012;205(9):465-9.

43. ALHOURANI E., RINCIC M., OTHMAN M., POHLE B., SCHLIE C., GLASER A. et al. Comprehensive chronic lymphocytic leukemia diagnostics by combined multiplex ligation dependent probe amplification (MLPA) and interphase fluorescence in situ hybridization (iFISH). Mol Cytogenet 2014;7:79.

44. KOSZTOLANYI S., KISS R., ATANESYAN L., GANGO A., DE GROOT K., STEENKAMER M. et al. High-Throughput Copy Number Profiling by Digital Multiplex Ligation-Dependent Probe Amplification in Multiple Myeloma. J Mol Diagn. 2018;20(6):777-788. 
45. YU C., LIN T., JOU S., LIN C., LIN K., LU M. et al. MLPA and DNA index improve the molecular diagnosis of childhood B-cell acute lymphoblastic leukemia. Sci Rep. 2020;10:11501.

46. RACK K., VAN DEN BERG E., HAFERLACH C., BEVERLOO H., COSTA D., ESPINET B. et al. European recommendations and quality assurance for cytogenomic analysis of haematological neoplasms. Leukemia. 2019;33;1851-1867.

47. WHEELER F., KIM A., MOSSE C., SHAVER A., YENAMANDRA A., SEEGMILLER A. Limited Utility of Fluorescence In Situ Hybridization for Recurrent Abnormalities in Acute Myeloid Leukemia at Diagnosis and Follow-up. Am J Clin Pathol. 2018;149(5):418-424.

Received $10^{\text {th }}$ December 2021 